\title{
As contribuições e os dilemas da crítica feminista para a análise do Estado de Bem-Estar Social /
}

Contributions and the dilemmas of feminist critics for the analysis of the Welfare State

Andréa SOUSA GAma*

Resumo: A finalidade desse trabalho é mapear os referenciais feministas de análise sobre o Estado de Bem-Estar Social e pontuar os dilemas contemporâneos evidenciados na literatura comparativa mais recente. Considerando que o objetivo da promoção da igualdade de gênero por políticas públicas trilha caminhos diferenciados na sua interpretação e proposição política, duas vertentes presentes na literatura são analisadas: a perspectiva da conciliação trabalho-família e a perspectiva da igualdade de gênero. A primeira vertente focaliza as desigualdades de gênero no mercado de trabalho, no interior da família e as variações das políticas sociais e de mercado de trabalho quanto ao nível de suporte oferecido aos pais e no quanto incentivam as divisões dos 'cuidados' e do trabalho remunerado. A segunda coloca o problema em termos igualitaristas na direção da neutralidade de gênero na alocação das oportunidades, condições de vida e resultados do bem-estar. Por fim, são levantados alguns questionamentos relativos às potencialidades e limites das políticas sociais brasileiras contemporâneas.

Palavras-chave: crítica feminista, Estado de Bem-Estar Social, gênero, políticas sociais.

Abstract: The purpose of this paper is mapping out the benchmarks of feminist analysis on the role of Welfare State and scoring the contemporary dilemmas highlighted in the most recent comparative literature. Whereas the objective of

* Mestre em Saúde Coletiva pela Escola Nacional de Saúde Pública (ENSP/Fiocruz), doutoranda na mesma Escola, professora assistente na Faculdade de Serviço Social da Universidade do Estado do Rio de Janeiro (UERJ).E-mail: andreasgama@gmail.com 
the promotion of gender equality in public policies tracks different paths in their interpretation, policy proposals analyze these two aspects in the literature: the prospect of work-family reconciliation and the prospect of gender equality. The first part examines the gender inequalities in the labour market, within the family and changes in social policies and labour market on the level of support offered to parents and encourage the divisions as 'care' and paid work. The second puts the problem in to egalitarian terms toward gender neutrality in the allocation of opportunities, living conditions and the results of welfare. Finally, the work raises some questions related to the potential and limits of the Brazilian contemporary social policies.

Keywords: feminist critics, Welfare State, gender and social policies.

\section{Introdução}

Embora os Estados de Bem-Estar Social contemporâneos tenham surgido em diferentes momentos e de diferentes formas, a partir da Segunda Guerra Mundial passam a partilhar um grau de similitude considerável. O núcleo central das reformas que os constituíram incluía a provisão de proteção social, assumida pelo Estado, às pessoas cuja pobreza resultava das dificuldades de, mediante o trabalho assalariado, se sustentarem devido a acidentes de trabalho, doença, desemprego e velhice. Consideravase que gozavam de um direito social, reconhecido como tarefa do Estado, e que esse direito, estava relacionado a uma concepção de cidadania. Mas, a variabilidade histórica da relação entre trabalho e cidadania nos faz pensar se podemos olhar para ela de forma diferente. Como pensar os direitos sociais das mulheres? Direitos de cidadania são para todos ou deve haver direitos diferenciados? De que forma as mulheres são cidadãs? A cidadania feminina passa pelo trabalho assalariado? $\mathrm{O}$ trabalho reprodutivo pode estar inscrito no âmbito da cidadania? Mulheres e cidadania, como elas entram no universo dos direitos? 
A construção dos Estados de Bem-Estar Social se assenta na divisão sexual do trabalho, onde as mulheres são alocadas como mães, esposas, cuidadoras e trabalhadoras no lar, mesmo quando também estão inseridas no mercado de trabalho, enquanto os homens sustentam economicamente as famílias por meio do trabalho remunerado.

A divisão sexual do trabalho e as ideologias de gênero ${ }^{1}$ (Hirata; Kergoat, 2007) que a acompanham vêm crescentemente sendo incorporadas aos processos de reforma dos Estados de Bem-Estar Social, sejam aquelas inspiradas em uma visão maternalista, sejam aquelas inspiradas nos ideais feministas igualitaristas. A partir da década de 1970, as feministas desenvolveram contundentes críticas aos sistemas de bem-estar social. No contexto do movimento de liberação das mulheres, a Conferência Internacional da Mulher, em 1975, reconheceu claramente a relevância do Estado para a solução do problema da dependência feminina aos homens, por meio da promoção da igualdade de oportunidades no trabalho e na educação, e da luta por igualdade salarial, creches, aborto e contracepção, medidas relacionadas à autonomia feminina de diferentes formas. Ao mesmo tempo, contudo, as relações entre o Estado e a família foram postas em evidência, principalmente, a forma pela qual o Estado sistematicamente estruturou a provisão de bem-estar social através do trabalho "invisível" da mulher. Desde então, as críticas às políticas sociais têm se ampliado e sustentado. Por um lado, a consciência de como o Estado constrói - por ser uma instância de organização da sociedade - e reconstrói - no âmbito político, no seu aparato e provisão - as desigualdades de gênero. Mas, por outro lado, o claro reconhecimento de que as mulheres necessitam de proteção social pública e demandam por ela.

\footnotetext{
De acordo com Hirata e Kergoat (2007, p. 596), pensar e estudar a divisão sexual do trabalho é: I) mostrar que as desigualdades entre homens e mulheres são sistemáticas; II) articular essa descrição do real como uma reflexão sobre os processos pelos quais a sociedade utiliza essa diferenciação para hierarquizar as atividades e os sexos, em suma, para criar um sistema de gênero.
} 
O crescimento da crítica feminista sobre o Estado de BemEstar Social é decorrente, basicamente, de duas vertentes, segundo Orloff (apud Faria, 1998). A primeira vertente, denominada feminista socialista, procura interpretar pela ótica do gênero as análises marxistas sobre determinadas características do sistema capitalista que o Estado de Bem-Estar Social reforça. Essa perspectiva sublinha as relações entre o capitalismo e o "patriarcado". 2 A segunda vertente centra a sua crítica sobre a teoria liberal e a teoria da democracia que teriam negligenciado as questões de gênero na análise da cidadania e da participação política (Faria, 1998).

Estudos comparativos recentes que examinam o Welfare State pela ótica do gênero têm em comum pelo menos cinco preocupações:

a) há uma demanda unânime de que tanto o trabalho remunerado quanto o não remunerado, sejam incluídos nas análises sobre o Estado de Bem-Estar Social;

b) o conceito de desmercantilização de Esping-Andersen deve ser reformulado para que ele possa ser adequadamente aplicado tanto aos homens quanto às mulheres;

c) há a necessidade de ampliação de pesquisas comparativas sistemáticas acerca do impacto de diferentes Welfare States sobre a condição da mulher;

d) os estudos que enfrentaram o desafio de comparar os regimes de bem-estar social a partir de uma perspectiva centrada na mulher sugerem que as tipologias propostas tanto podem se assemelhar aos "regimes de gênero" quanto apresentar importantes divergências, e, por último,

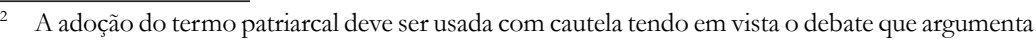
que o patriarcado perdeu sua força com o desmonte do provedor masculino.
} 
e) os estudos feministas mostram que a divisão do trabalho entre os sexos e as ideologias de gênero influenciam a provisão de proteção social e que as políticas sociais afetam de maneira distinta as condições de vida de homens e mulheres nos diferentes tipos de Estado de Bem-Estar Social.

Este último conjunto de preocupações conforma o core do diagnóstico e das propostas políticas engendradas por teóricas e militantes feministas (Faria, 1998, p. 68).

O objetivo da promoção da igualdade de gênero por políticas públicas trilha caminhos diferenciados na sua interpretação e proposição política, com a ressalva de suas interconexões. A primeira vertente nasce da tradição maternalista e mantém alguns de seus traços na perspectiva da conciliação trabalho-família. A segunda coloca o problema em termos igualitaristas na direção de uma "neutralidade" de gênero na alocação das oportunidades e condições de vida.

Há uma tendência generalizada de polarizar o debate pela insistência de optar por isso ou aquilo, de opor igualdade e diferença, autonomia e dependência, direitos individuais e identidades de grupos. Nessa viagem pela crítica feminista, tentarei mostrar, seguindo o argumento de Scott (2005), que igualdade e diferença não são opostos, mas conceitos interdependentes que estão necessariamente em tensão e que essas tensões na relação com o Estado se resolvem de formas historicamente específicas e necessitam ser analisadas nas suas contingências políticas particulares. O movimento feminista surge embebido nesses dilemas e ao analisar a produção científica sobre gênero e Estados de Bem-Estar social essas tensões se atualizam.

O objetivo principal deste trabalho é mapear os referenciais feministas de análise sobre o Estado de Bem-Estar Social e pontuar os dilemas contemporâneos evidenciados na literatura comparativa mais recente. 


\section{A perspectiva da conciliação trabalho-família}

Estudos históricos recentes (Bock, 1994, Lefaucheur, 1994) têm mostrado que os primeiros movimentos de mulheres $\left(1^{\text {a }}\right.$ onda) tiveram um papel decisivo na criação e nas reformas dos sistemas de proteção social contemporâneos, nomeadamente as que dizem respeito às mães e à maternidade. As reivindicações feministas dirigiam-se à maternidade per si, independentemente da pobreza das mulheres e do seu estado civil ou estatuto profissional, argumentando que aqueles grupos específicos de mães eram versões extremas de uma condição feminina universal: ser ou poder ser mãe e depender dos homens para a sua subsistência e a dos seus filhos. Esta preocupação com o bem-estar das mães, que foi descrita por Bock como "feminismo maternalista assentava-se no pressuposto de que a maternidade era a condição unificadora do sexo feminino e da sua subjugação. Ela questionava tanto a pobreza feminina como o salário familiar do marido e levava da reivindicação dos direitos das mães pobres à reivindicação dos direitos de todas as mães” (Bock, 1994, p. 437 - grifo meu).

Nesse contexto, os movimentos de mulheres lutaram por um tipo de Estado-providência e de cidadania que reconhecesse os direitos e as necessidades relacionadas com os riscos não só dos assalariados masculinos, mas também das mães, assalariadas ou não. Eles inspiraram e modelaram uma importante legislação sobre proteção social em diversos países, como licenças e subsídios de maternidade, abono ou salário-família. Entretanto, essas legislações não realizaram plenamente as suas reivindicações, posto que geralmente eram implementadas mais com um caráter paternalista, do que como direitos (maternalistas).

Uma questão crucial no debate feminista é a atividade que as mulheres realizam enquanto mães e que muitas feministas consideram pertencer ao domínio do trabalho. Grande parte das feministas maternalistas do início do século XX lutava pela dignidade da maternidade, pelo seu reconhecimento como trabalho 
e pela remuneração universal ou parcial do Estado. A denúncia de que o trabalho da mulher para o marido era uma condição sine qua non da empregabilidade deste significava que a sociedade devia o reconhecimento social, político e econômico do seu trabalho doméstico. Idéias e propostas segundo as quais a maternidade devia ser reconhecida como trabalho, remunerada com um salário e, portanto, subvencionada pelo Estado eram consideradas um veículo para a independência (financeira) das mães e para uma mudança fundamental nas relações entre os sexos. Nessa direção, Bock (1994, p. 451, 452) afirma:

As feministas que insistiam em que a maternidade é uma função social e não apenas uma função fisiológica, privada ou individual desafiaram a dicotomia cultural tradicional entre a esfera privada/pessoal e a esfera pública/política e lutaram por uma nova concepção da sua relação não só a respeito da sociedade extradoméstica, mas também a respeito do lar e da maternidade.

Agora as mulheres reivindicavam os seus direitos de cidadania invocando a sua própria "natureza", que consideravam ser um contributo único para a sociedade. Ao exigir direitos, recompensas e proteção para o que até então tinham sido os seus deveres privados e individuais, não questionavam tanto a repartição do trabalho entre homens e mulheres, mas, sobretudo, a divisão, baseada no sexo, entre trabalho não remunerado e trabalho remunerado (ambos deveriam ser pagos consoante o seu valor).

Bock (1994) destaca, entretanto, algumas objeções à análise da maternidade como um trabalho social, tais como a "imoralidade" de se transformar o "trabalho do amor" de valor de uso em valor de troca e da liberalização dos homens da sua responsabilidade perante a mulher e filhos, minando por esse motivo os incentivos ao trabalho masculino. Apesar dessas objeções, a maior parte das feministas de então, incluindo as que rejeitavam o subsídio de 
maternidade, utilizaram a ideologia da maternidade na elaboração das suas concepções sobre a emancipação das mulheres. Fica evidente que, por mais valorizados ou rebaixados que fossem, a maternidade e o trabalho doméstico eram tarefas de mulheres. A valorização da mulher adviria da valorização da maternidade como um trabalho necessariamente útil para a sociedade.

Tais feministas exigiam a igualdade com os homens a partir do direito das mulheres a serem diferentes, entendendo esta posição como uma expressão de auto-afirmação e não da sua falta de poder. Elas não partilhavam a idéia de que para serem "iguais" as mulheres deveriam aceitar os valores sociais dominantes centrados no homem; em vez disso, esperavam miná-los, substituí-los ou, pelo menos, complementá-los. As feministas francesas resumiram esta idéia na expressão "a igualdade na diferença".

Bock (1994), em seu frutífero trabalho, realiza um inventário da legislação de proteção social das mães em diversos países com o intuito de melhorar o cuidado com as crianças - principalmente as pobres ou aquelas em que ambos os pais trabalhavam - que eram freqüentemente entregues a instituições públicas. Além disso, contribuía para a proliferação dessa legislação, o crescente declínio das taxas de fecundidade. Portanto, a pobreza das famílias e a questão populacional eram vistas como as causas mais importantes para a multiplicação das medidas públicas de proteção social à maternidade. Embora tenha produzido mudanças positivas para as mães e o Estado assumido, mesmo que de forma parcial, essa tarefa, tal legislação não foi uma resposta direta às reivindicações feministas ou à difícil situação das mães.

Durante e após a $2^{\text {a }}$ Guerra Mundial, ocorre a passagem dos benefícios relacionados com a maternidade para os abonos centrados na família. A Lei dos Abonos de Família universais financiados pelo Estado, como recomendado pelo Relatório Beveridge (1942) com o claro intuito de manter a capacidade de consumo do trabalhador com filhos, representou uma derrota para 
os objetivos originais do feminismo maternalista. Paralelamente, diversos grupos feministas opunham-se às políticas centradas na maternidade e lutavam por disposições legais idênticas e pela igualdade entre homens e mulheres, dando origem a uma profunda clivagem no seio das comunidades feministas da Inglaterra e dos EUA. Com efeito, o crescimento da economia industrial monopolista, a ampliação do emprego e das condições de trabalho fez com que as mulheres considerassem mais fácil conseguir a emancipação pelo trabalho assalariado e pela redistribuição de responsabilidades entre o casal do que através do reconhecimento público da maternidade como uma função social.

A crescente participação feminina no mercado de trabalho levou ao questionamento - ou mesmo ao abandono - das premissas maternalistas durante os anos 1960 e 1970. Entretanto, os movimentos de mulheres ( $2^{\mathrm{a}}$ onda) não abandonaram a necessidade da provisão estatal, principalmente decorrente das intensas transformações da família e da organização do trabalho. Em face da escolha entre a dependência ao homem, por um lado, e a dependência ao Estado e ao assalariamento, por outro, as feministas preferiram o Estado e o trabalho assalariado. Porém, novos contornos se estabelecem para a questão da maternidade, notadamente para a sua conjugação com o trabalho remunerado.

Uma questão básica para qualquer arquitetura do bem-estar é como alocar a sua produção. Esse tipo de exercício analítico evidencia, segundo Esping-Andersen (2002), a interdependência dos três pilares do bem-estar - o mercado, a família e o Estado. No entanto, apesar da inexistência de uma concepção unívoca de direitos sociais quanto aos distintos papéis atribuídos a cada um desses pilares, a crítica feminista vai incidir com contundência sobre o papel das mulheres na provisão do bem-estar por meio do trabalho doméstico não remunerado e do trabalho de assistência ${ }^{3}$ exercido na esfera da reprodução social.

3 Algumas autoras definem esse trabalho como care (cuidado). 
Esping-Andersen, em seu trabalho Why we need a new Welfare State (2002), defende a necessidade de um novo contrato social amigável às mulheres ao destacar os novos riscos sociais inerentes à nova inserção feminina no mundo do trabalho e na esfera familiar, bem como o impacto no sistema de proteção social, a partir das novas demandas femininas que contribuíram para desestabilizar os primeiros acordos de gênero, família e trabalho. $\mathrm{O}$ autor propõe quatro arenas políticas fundamentais para a reconstrução do modelo de bem-estar, quais sejam: crianças e famílias, relações de gênero, vida de trabalho e aposentadoria. Tais áreas representam o alicerce das chances de vida dos cidadãos e são os maiores desafios do ponto de vista da adaptação ao modo de vida pós-industrial. Defende que as mulheres podem ocupar o centro da sociedade pós-industrial, assim como os homens foram os grandes protagonistas do alto industrialismo. Trilhando seu argumento, a ascensão do emprego feminino esteve fortemente assentada na emergência da economia de serviços que, por sua vez, foi também alavancada pela entrada da mulher no mercado de trabalho. A economia de serviços como o resultado de novas tecnologias e de mudanças nas relações financeiras e de produção também é decorrente das mudanças no comportamento das famílias pelo quase desaparecimento do modelo da mulher do lar e das empregadas domésticas e pela ampliação do emprego de mães e esposas. $\mathrm{O}$ aumento da participação feminina no mercado de trabalho implicou uma dupla dimensão do emprego, visível no âmbito do consumo de massa e na capacidade aquisitiva das famílias.

No entanto, esse autor peca ao refuncionalizar o papel das mulheres no contexto das reformas atuais dos Estados de Bem-Estar Social. Em primeiro lugar, ele não aprofunda as transformações do trabalho, as novas formas de produção e emprego, e o seu impacto diferenciado para homens e mulheres. Considerando-se que ter duas fontes de rendimento passou a ser uma necessidade econômica para um número cada vez maior de 
famílias, o aumento do desemprego e a maior oferta de vagas no setor de serviços, onde muitos empregos são mal remunerados, de baixa qualificação e de tempo parcial, subavaliar o caráter e a dimensão dessas mudanças para homens e mulheres significa naturalizar a inserção desigual das mulheres no mercado de trabalho atual.

Em segundo lugar, ao propor políticas de família fortemente orientadas nas condições econômicas e sociais da infância, base da sua proposição do life course framework (padrão do curso de vida) e do investimento em capital humano - condição para a eficiência na dinâmica competitiva da economia do conhecimento e veículo de equalização de oportunidades - tende à minimização das reivindicações das mulheres posto que fortemente assentada na efetividade do emprego das mães para a prevenção da pobreza das crianças. Nessa direção, as políticas de equidade de gênero serão conformadas, em sua maioria, pela conciliação de maternidade e emprego, onde o trabalho feminino será fundamental para manter as famílias acima do nível de pobreza, contribuir para o financiamento da Previdência Social e ser uma das peças-chave do equilíbrio da economia pós-industrial (Esping-Andersen, 2002).

Refletindo sobre o significado dessa mudança histórica em termos da concepção do Estado de Bem-Estar Social sobre as mulheres, temos as políticas amigáveis às mulheres (women-friendly policy) como as soluções mais consensuais no corrente debate político para solucionar os trade-offs criados por uma nova realidade das preferências de gênero - a conciliação trabalho-maternidade (Esping-Andersen, 2002).

A demanda atual por esse equilíbrio também é resultado das políticas neoliberais que precarizaram o trabalho, causando sua desvalorização e intensificação, e que polarizaram os mercados de trabalho, ao mesmo tempo em que a força de trabalho se feminizou, aumentando as diferenças entre mulheres de classes sociais diferentes. 
Essa é muito mais uma questão de equidade do que de igualitarismo. É uma questão de equidade se os trade-offs envolvidos incorrem em custos que são alocados desfavoravelmente para as mulheres e estão invariavelmente mais relacionados a um viés de classe social. Esse é um dos principais argumentos em favor das políticas amigáveis às mulheres na redução de tais desigualdades. $\mathrm{Na}$ União Européia, por exemplo, o equilíbrio trabalho-vida familiar passou a ser uma prioridade de governo.

A compatibilidade trabalho-família está contingenciada pela natureza do suporte institucional. Além disso, diversos estudos comparativos recentes vêm mostrando que existem respostas políticas muito diferenciadas para as mesmas demandas (Orloff, [s.d.], Meulders, et al., 2007, Torres; Mendes; Lapa, 2007, Gornick; Meyers, 2007).

O trabalho de Crompton e Lyonette (2007), por exemplo, aponta que conjugar trabalho e família está eivado de pressões e tensões e que os níveis desse conflito variam com as circunstâncias nacionais, individuais e familiares. Ao desenvolver um estudo comparativo sobre os níveis de conflito trabalho-vida familiar de famílias com duplo rendimento, a partir de fatores como presença de crianças no lar, média de horas semanais trabalhadas, classe social, programas de Estado e divisão doméstica do trabalho, as autoras concluem que os índices de tais conflitos são menores quando há um forte apoio dos governos para as famílias com dois provedores de rendimento. Contudo, também ponderam que o

apoio estatal é uma condição necessária, porém, não suficiente para se chegar ao "equilíbrio" trabalho-vida familiar, pois a divisão por gênero do trabalho doméstico também é importante. Se o trabalho doméstico for transferido para outras mulheres (como empregadas remuneradas) haverá menos pressão sobre os homens e as desigualdades entre as mulheres aumentarão. (Crompton; Lyonette, 2007, p. 128).

Esses estudos que analisam a problemática da conciliação entre trabalho remunerado e responsabilidades familiares têm 
operado análises a partir das mudanças na estrutura das famílias e no mercado de trabalho. Em geral, comparando as realidades européia e norte-americana, buscam analisar as desigualdades de gênero no mercado de trabalho, no interior da família e as variações das políticas sociais e de mercado de trabalho quanto ao nível de suporte oferecido aos pais e no quanto incentivam as divisões dos 'cuidados' e do trabalho remunerado com base na igualdade de gênero. Procuram, ainda, mensurar os efeitos da maternidade e da paternidade sobre as condições e perspectivas de trabalho de homens e mulheres, bem como o papel e a eficácia das políticas públicas em apoio ao modelo onde ambos os cônjuges trabalham. Apesar das diferenças entre os países no tocante à estrutura das famílias e à composição sexual do mercado de trabalho, em geral reconhecem o impacto qualitativo e quantitativo da intervenção estatal na compatibilização família-trabalho.

Os efeitos diferenciados da paternidade e da maternidade sobre a participação no trabalho perfazem a ampliação da inserção no mercado de trabalho e o aumento do número de horas trabalhado resultante das pressões econômicas com o aumento da família, para os homens, e o impacto negativo sobre o trabalho das mulheres, levando-as ao trabalho em tempo parcial, à diminuição da remuneração e à inatividade, principalmente, quando as crianças ainda são pequenas (Sorj; Fontes, 2007, Crompton; Lyonette, 2007).

Desafiadas por aquilo que consideravam uma "falta de sensibilidade" para as questões de gênero nas teorias e modelos do Estado de Bem-Estar Social, diferentes teóricas, feministas ou não, passaram a desenvolver análises comparativas e de construção de tipologias, agora com a tarefa de analisar o gênero e os regimes de bem-estar social.

Gornick e Meyers (2007), por exemplo, apresentam as variações das políticas sociais e de mercado de trabalho na Europa e EUA quanto ao nível de suporte oferecido aos pais e o quanto incentiva as divisões dos 'cuidados' e do trabalho remunerado 
com base na igualdade de gênero. Analisando os diferentes regimes de bem-estar social com relação a trabalho remunerado e 'cuidados' apresentam resultados relativos, principalmente, a três formas de intervenção pública: as políticas de licença-família, as regulamentações da jornada de trabalho e os serviços de educação e cuidado infantil. Ao sugerir a adoção de um modelo com dois provedores de renda/dois provedores de 'cuidado', as autoras destacam os países social-democratas como os mais bemsucedidos na promoção da igualdade de gênero que valoriza tanto o trabalho remunerado como o bem-estar infantil.

Por outro lado, Orloff (s. d.) ao analisar a trajetória políticoinstitucional das políticas que envolvem o "adeus ao maternalismo", a partir de dois modelos completamente distintos - o modelo sueco e o modelo americano -, desmistifica-os destacando que ambos apresentam lacunas no objetivo da igualdade de gênero nas esferas do trabalho e do cuidado. $\mathrm{Na}$ Suécia existe uma série de políticas que viabilizam a conciliação entre trabalho e família, na qual as mulheres são as maiores beneficiárias. A social-democracia tem um papel importante nesse cenário. Sua agenda política visa a promover a igualdade de gênero através do emprego feminino e da criação de serviços públicos. As mulheres contam com uma ampla rede de serviços públicos voltados para o 'cuidado', o que tem contribuído para a “desfamiliarização” do ‘cuidado’. Porém, apesar das altas taxas de empregabilidade, as mulheres ocupam os cargos menos prestigiosos e estão muito vinculadas ao setor público, caracterizando uma forte segmentação no mercado de trabalho. As políticas suecas fazem o trabalho feminino ser compatível com a maternidade, mas não fazem o mesmo para o trabalho masculino, reforçando a prerrogativa feminina do 'cuidado'. Considera que o modelo sueco do duplo rendimento não pode ser tomado como referência para todos os países, na medida em que existem contextos sociais e políticos altamente diferenciados. 
O modelo americano do "trabalho para todos" desenvolve políticas de gênero orientadas pelo mercado. O grande incentivo ao trabalho remunerado das mulheres faz com que elas recebam uma maior remuneração e haja uma diminuição da distância salarial entre homens e mulheres, além de elas ocuparem cargos mais altos e reconhecidamente "masculinos". A diversificação do mercado de trabalho entre homens e mulheres tem fortes raízes no feminismo liberal norte-americano, fundamentado nas noções de justiça e direitos individuais e na adoção de políticas de ação afirmativa. Entretanto, o Estado não intervém no 'cuidado', pois é entendido como um assunto privado, de escolha individual. Ao Estado cabe o papel de criar oportunidades de trabalho mais igualitárias. Apesar dos altos níveis de empregabilidade feminina e com relativamente menor taxa de emprego de tempo parcial, existe um gaph nas taxas de emprego de mães de crianças pequenas que, pela compreensão do 'cuidado' restrita ao lócus do privado e a sua intensa mercantilização, enseja grandes desigualdades sociais entre as mulheres e as famílias. Após a reforma do sistema de proteção social americano, em 1996, o objeto das políticas sociais se restringe às mulheres pobres e, principalmente, às chefes de família, mediante programas de workfare. Há incentivos à provisão do setor privado de 'cuidados', através da dedução de impostos para o cuidado das crianças. $\mathrm{O}$ aumento das desigualdades entre as mulheres está estreitamente relacionado com os custos do 'cuidado', onde, por exemplo, as mulheres imigrantes ocupam um lugar importante nesse mercado. Expressam, ainda, essas desigualdades as maiores taxas de desemprego e de trabalho em tempo parcial entre mulheres pobres com filhos pequenos. A esse respeito, Orloff (s. d.) considera que, apesar dos avanços das mulheres americanas na economia e talvez em suas vidas pessoais, o dilema americano reside na necessidade de se promover um "suporte neutro de gênero" para as trabalhadoras com responsabilidades com os cuidados.

Fechando suas análises, a autora enfatiza que a liberalização da economia traz como prioridade a empregabilidade, e as políticas 
direcionadas ao ‘cuidado' vão sendo erodidas, sejam elas prestadas em serviços ou em benefícios em dinheiro. Isso tende a aumentar a participação feminina no mercado de trabalho, principalmente no setor mais flexível da economia que é o de serviços, onde estão os empregos em tempo parcial, temporários, de mais baixa remuneração, e a reprivatizar o ‘cuidado' na família, por meio de subsídios em renda para as crianças, ou mesmo através do mercado. Sugere como alternativa, o modelo do "cuidador universal" ("Universal caregiver" model) para homens e mulheres e a transversalização da política do 'cuidado' entre Estado, família e mercado. Quando faz referência aos limites da mercantilização ou da estatização do 'cuidado' e à impossibilidade da sua total paridade, pondera que ele deve ser valorizado como uma atividade humana, como parte intrínseca da vida social e na qual todas as instâncias devem estar envolvidas.

Para concluir esta parte do trabalho, penso que seria importante apresentarmos aqui as análises de Jane Lewis (2001), que, reconhecendo a relação entre trabalho remunerado, não remunerado e bem-estar social, sugere a construção de modelos de Estado de Bem-Estar Social a partir de uma tipologia alternativa: países em que o padrão homem-provedor (male breadwinner) é forte, modificado ou fraco. Para pensar os diferentes regimes de Estado de Bem-Estar Social, Lewis elege como principais variáveis:

a) os Estados de Bem-Estar Social estão fundados no padrão do homem-provedor e da mulher dependente do homem trabalhador, pelas pensões e outros benefícios;

b) deve-se colocar no centro da análise as relações de gênero em associação com a relação capital versus trabalho;

c) trazer a família e o trabalho não remunerado (para essa autora, o 'cuidado') como parte do regime de proteção social;

d) nas análises comparativas dos Estados de Bem-Estar Social, deve-se considerar a participação feminina no 
mercado de trabalho e o nível de empregabilidade das mulheres como um indicador do nível de bem-estar - o emprego feminino é a saída da dependência dos benefícios sociais através dos homens e da dependência ao casamento;

e) deve-se analisar a cobertura dos Estados de Bem-Estar Social para o 'cuidado', através dos serviços e provisões gerados pelo Estado, família e mercado para aqueles que necessitam de cuidados.

Lewis (2001) propõe a passagem do modelo do homemprovedor para o modelo do adulto trabalhador (adult-worker model) e que existem seis possibilidades de transição para esse modelo, onde a posição de homens e mulheres no mercado de trabalho organiza a gestão dos cuidados entre família, Estado e mercado. Não irei destacar cada um deles, mas sim as ambigüidades ainda presentes no atual modelo de políticas públicas. Em primeiro lugar, o modelo do adulto-trabalhador abarca um homem e uma mulher provedores, porém, com status diverso porque o trabalho não remunerado ainda carece da devida relevância pública. Em segundo lugar, as mudanças na família foram mais acentuadas, em termos das mudanças de gênero, do que aquelas no mercado de trabalho, pela maior individualização e pela descomplementariedade dos papéis de homens e mulheres na família. Não obstante a acentuada mudança da participação feminina no mercado de trabalho, esta ainda ocorre em situação desfavorável para as mulheres (trabalho parcial, precário, etc), pois segundo a autora, a permanência delas no trabalho não remunerado impacta desfavoravelmente na sua inserção produtiva e corrobora o atributo do 'cuidado' às mulheres. Como, então, promover uma outra posição da mulher no mercado de trabalho? Considera que seja através da promoção do trabalho em tempo integral ou complementando a renda daquelas que não conseguem sair do trabalho parcial, bem como de políticas direcionadas ao trabalho não remunerado, combinadas entre provisão de serviços e benefícios em dinheiro. 
Jenson (1997) se contrapõe às análises de Lewis das contradições dos sistemas de bem-star social ao sugerir uma tipologia do Estado de Bem-estar Social, a partir do 'care'. Defende a introdução do 'cuidado' - Quem cuida? Como o cuidado é desenvolvido? Quem financia o cuidado? - como central na definição dos modelos de Estado de Bem-Estar Social, subordinando o trabalho nessa definição. Nessa perspectiva, segundo um olhar de igualdade de gênero no cuidado, o modelo sueco estaria em baixa nessa tipologia. E completa, perguntando: quais as conseqüências de um regime de 'care' para a eqüidade de gênero?

\section{A perspectiva da igualdade de gênero}

O segundo objetivo, para outro grupo de feministas, no tocante aos Estados de Bem-Estar Social e gênero é muito mais ambicioso e visa à total neutralidade de gênero na alocação das oportunidades, chances de vida e nos resultados do bem-estar. Em sua formulação mais radical, qualquer desigualdade que esteja relacionada a gênero implica discriminação sexual. No debate contemporâneo, os objetivos de igualdade geralmente se referem à segregação no mercado de trabalho, à diferenciação salarial para o mesmo trabalho e à distribuição assimétrica do trabalho não remunerado.

Como assinalei anteriormente, os dois objetivos apresentados neste trabalho estão muito misturados e as análises e resultados de pesquisa apresentados no item anterior poderiam estar perfeitamente inseridos aqui. Quando as autoras citadas discutem que, para a promoção de maior igualdade de gênero, as políticas devem concentrar-se no comportamento masculino, com vista ao equilíbrio das responsabilidades do trabalho não remunerado (care) combinadas com a maior igualdade no mercado de trabalho, poderia inserí-las neste tópico. 
Em um crescente número de países desenvolvidos e em alguns em desenvolvimento, as curvas de participação das mulheres no mercado de trabalho têm se assemelhado à dos homens, bem como o nível de escolaridade. Além disso, começa-se a observar a erosão do curso de vida masculino diante da instabilidade do emprego e do desemprego, principalmente entre homens jovens e com baixa qualificação. Isso vem provocando uma tendência de maior aproximação nas características de inserção no trabalho entre homens e mulheres (Esping-Andersen, 2002). Entretanto, em uma maior convergência ou não, as tensões da igualdade de gênero permanecem, porque as forças que impelem a convergência também criam e aprofundam desigualdades de segunda ordem, particularmente aos obstáculos relacionados com a segregação e discriminação de gênero no mercado de trabalho, condições precárias no trabalho e a divisão desigual do trabalho doméstico. Foi pensando nessas contradições que procuro, neste momento, trazer discussões mais direcionadas à esfera do trabalho, da reprodução social e da natureza do Estado de Bem-Estar Social.

McIntosh (2000) analisa as estratégias do feminismo da diferença e do feminismo igualitarista e apresenta crítica produtiva em relação a ambas. Defende que a luta feminista tem que juntar o âmbito da produção e da reprodução onde a exploraçãodominação se dá. A perspectiva que ressalta o alcance da igualdade de gênero por meio do fortalecimento dos laços das mulheres com o trabalho, muitas vezes deixa de considerar que a inserção delas no mercado de trabalho como ele está organizado tende a forçá-las a se integrar em condições subalternizadas - trabalhos precários, mal remunerados - aumentando a sua dependência e colocando outras mulheres em condições de desigualdade. Já a perspectiva do feminismo da diferença, segundo a autora, apenas suaviza o problema, com pouco impacto sobre mudanças efetivas nas condições das mulheres. Acrescenta, ainda, as fragilidades sempre presentes na abordagem da política social que focaliza as questões de igualdade de renda em termos dos resultados dos 
processos redistributivos e não focaliza a estrutura das relações envolvidas na produção desses resultados. Propõe a mudança do fim do casamento como unidade básica do sistema de seguridade social, contribuindo para o afrouxamento dos laços do sistema de bem-estar social em geral. Essa perspectiva de autonomização busca ainda lutar contra os cortes que forçam as mulheres a se encontrarem em situação de dependência, tanto aqueles que favorecem a perda dos seus empregos, como aqueles que aumentam o trabalho não remunerado.

A posição que a autora tem defendido baseia-se numa contundente crítica ao assalariamento e aos sistemas de bem-estar social que ocultam a separação "patriarcal" entre produção e reprodução social. A característica específica da opressão feminina até hoje estaria, segundo essa autora, relacionada à articulação entre o sistema salarial e o sistema familiar. No entanto, a despeito de todas as desvantagens do trabalho assalariado, o caminho para superá-lo passa pelo incremento da inserção feminina no mundo do trabalho, resgatando-a da dependência "pré-proletária" (McIntosh, 2000).

Essa concepção considera que a ideologia de gênero dificulta a percepção da relevância do trabalho doméstico das mulheres, deixando a impressão de que elas são dependentes dos maridos, embora a organização do trabalho deles e a mais-valia do seu empregador também se beneficiem desse trabalho feminino invisível (Giffin, 2006, p. 645).

Historicamente, com a separação do âmbito da produção e da reprodução social, com a emergência da família nuclear burguesa e da sociedade de mercado percebemos os dois lados da mesma moeda: o trabalho remunerado das mulheres foi assentado de forma subalterna, ao mesmo tempo, que o trabalho não remunerado ficou invisível, mas, por outro lado, ele também não foi mercantilizado, por não ter valor de troca. No capitalismo ocorre uma re-atualização das relações de dominação, agora 
associado com a dimensão da exploração. A crítica feminista, portanto, cria dilemas e novas questões políticas, tanto ao publicizar a funcionalidade do trabalho não remunerado, quanto ao propor mercantilizá-lo. Em outras palavras, o jogo da dependência e da autonomia nas esferas da produção e da reprodução social é permanente e atravessa a estrutura dos sistemas salarial e de bem-estar.

Pateman (2000) aprofunda o desvelamento da estrutura "patriarcal" do Estado de Bem-Estar Social ao destacar as implicações democráticas do direito ao trabalho que não podem ser compreendidas sem a devida atenção às conexões existentes entre o mundo público do trabalho e da cidadania e o mundo privado das relações conjugais. Isso significa que ser um Trabalhador (enquanto categoria social) depende do seu status de homem, do seu poder como marido e da sua posição como cidadão perante o Estado. A construção do trabalhador masculino como provedor e da sua esposa como dependente foi oficialmente consagrada por uma série de legislações que conformaram e consolidaram o Estado de Bem-Estar Social. Logo, este se estrutura sobre uma divisão do trabalho por gênero. Essa divisão estrutura, inclusive, a provisão de bem-estar. Primeiro há os benefícios disponíveis para os trabalhadores individuais por sua participação no mercado, em geral, benefícios reivindicados pelos homens. Em segundo, existem aqueles disponíveis para os indivíduos dependentes dos da primeira categoria, geralmente reclamados pelas mulheres. No debate sobre o Estado de Bem-Estar Social e o salário social, o salário é usualmente tratado como um retorno pela venda da força de trabalho individual. Entretanto, com a intensificação da exploração da força de trabalho e da consolidação do modelo marital provedor/dona-de-casa, a luta entre capital e trabalho passou a se estabelecer pelo salário socialmente necessário para a subsistência do trabalhador e de sua família: "O salário não é aquele suficiente para reproduzir a capacidade de trabalho, mas o que é suficiente, na combinação com o trabalho não remunerado da mulher, para reproduzir a força de trabalho presente e futura" (Pateman, 2000, p. 137). 
Em geral, as análises feministas que buscam a integração do trabalho não remunerado às teorias e tipologias do Estado de Bem-Estar Social assentadas na provisão de bem-estar entre Estado, mercado e família denunciam que esse trabalho doméstico não remunerado jamais poderia ter sido negligenciado. EspingAndersen, por exemplo, apesar de defender a necessidade de se investigar a interação entre esses três provedores de bem-estar, acabou relegando a um segundo plano o papel da família. Aliás, o desenvolvimento do Estado de Bem-Estar Social está assentado no pressuposto de que certos aspectos do bem-estar podem e devem continuar a ser promovidos pelas mulheres em casa, como parte da sua responsabilidade na esfera privada, e não através de provisão pública. Um exemplo atual, a partir dos processos de reforma dos Estados de Bem-Estar Social tem sido o processo de assistencialização e filantropização das políticas sociais que vem ocorrendo em muitos países, assentado no corolário de que as mulheres cuidam melhor do que os homens. Pateman (2000) fornece vários exemplos de como o Estado de Bem-Estar Social reforça a identidade feminina como dependente dos homens, tanto direta, como indiretamente, por meio de legislações de proteção como aposentadorias e pensões, dos sistemas de taxação como um sistema de transferência de renda, entre outros.

A crítica "patriarcal" do Estado de Bem-Estar Social é apenas uma parte da figura. O desenvolvimento dos sistemas de bem-estar social tem também trazido desafios ao poder "patriarcal" e ajudado a prover uma base para a cidadania autônoma das mulheres. Entretanto, a questão de como as mulheres podem se tornar cidadãs plenas de um Estado de Bem-Estar Social democrático é mais complexa do que pode parecer ao primeiro olhar. De acordo com Pateman (2000), o dilema da cidadania feminina que orienta a luta feminista opõe igualitaristas (agenda neutra de gênero) e diferencialistas (proteção às necessidades sociais diferenciadas) na construção de duas alternativas - ou tornam-se como homens ou continuam o trabalho "feminino" que não tem valor para a égide 
da cidadania. Isso significa que permanecem dando um sentido "patriarcal” à cidadania e ao Estado de Bem-Estar Social.

No sentido patriarcal da cidadania, as mulheres não podem ser cidadãs plenas, na melhor situação podem ser consideradas como menos homens. Ao mesmo tempo, no interior de um Estado de Bem-Estar Social patriarcal, demandar reconhecimento social e suporte para as responsabilidades das mulheres significa condená-las à incorporação na vida pública como mulheres, ou seja, como membros de uma outra esfera que não têm o mesmo reconhecimento dos concidadãos masculinos. (Pateman, 2000, p. 142).

A autora analisa historicamente esse dilema em alguns países e a sua correlacionada estrutura de benefícios, apresentando os problemas das mulheres como trabalhadoras e apontando as potencialidades e limites no interior dos Estados de Bem-Estar Social.

\section{Mais perguntas do que conclusões}

Atualmente, um dos maiores desafios postos para os pesquisadores do Estado de Bem-Estar Social parecer ser não apenas continuar a fertilização entre as análises das ciências sociais e a perspectiva de gênero, mas também encarar a tarefa de dialogar com os analistas da retração/adaptação do Estado de Bem-Estar Social. Um longo percurso de pesquisa e de luta política deve chamar a atenção para as diferentes maneiras através das quais as estratégias de reforma dos Estados de Bem-Estar Social podem afetar a situação dos assalariados e das mulheres nessa ordem mundial de primazia do capital.

Pretendo, por fim, levantar alguns questionamentos relacionados às potencialidades e limites das políticas sociais brasileiras contemporâneas no tocante à promoção da igualdade de gênero. 
As intensas transformações do mundo do trabalho associadas às mudanças na estrutura das famílias renovam as contradições no papel e na provisão dos Estados de Bem-Estar Social. No Brasil, isso é particularmente verdade quando levamos em conta que quase a metade da força de trabalho encontra-se no mercado informal de trabalho e onde as mulheres são maioria; que o sistema previdenciário se estrutura sobre o mercado formal de trabalho; que temos uma retração nas taxas de fecundidade e um aumento nas taxas de envelhecimento da população; que existe uma baixa cobertura do sistema de educação e cuidado de crianças pequenas e que a assistência social reforça o lugar da mulher como cuidadora/beneficiária.

Temos ainda o confronto de duas perspectivas: a FAMÍLIA deve organizar centralmente as políticas sociais e a igualdade de gênero será buscada em articulação com essa, ou deve ser o TRABALHO FEMININO/PROTEÇÃO SOCIAL À MULHER o centro da análise e da formatação das políticas sociais que visam à igualdade de gênero?

Qual seria o melhor caminho ou opção de resposta pública diante da crescente inserção feminina no mercado de trabalho e a conciliação entre o trabalho e a vida familiar no Brasil? Por que essa questão da conciliação trabalho-família encontra pouca visibilidade política na sociedade brasileira, ilustrada, por exemplo, na baixíssima cobertura de equipamentos de cuidado infantil, como creches e escolas de horário integral, que facilitariam e até mesmo permitiriam a entrada das mulheres no mercado de trabalho de forma mais qualificada - porque crescentemente ampliam o seu nível de escolaridade - e em igualdade de condições com os homens? Será que essa pouca visibilidade tem a ver com o forte familismo (centralidade da família como força social e política fundante da nossa sociabilidade) e maternalismo (status feminino fortemente ligado à reprodução e à família) da sociedade brasileira que atribui a responsabilidade do cuidado às mulheres e que o Estado reforça e reproduz? Será que as dificuldades nessa 
conciliação associadas à estagnação da renda das famílias, mesmo com o trabalho feminino agora necessário para a manutenção do consumo e para a prevenção da pobreza das famílias estariam na base da acentuada queda da natalidade no Brasil? Vamos continuar mantendo como saída para a conciliação trabalho-família das mulheres das camadas médias e altas o emprego doméstico - que perfaz a maior categoria profissional no Brasil e onde se encontram as mulheres negras, mais pobres e com menos direitos trabalhistas - mantendo a desigualdade social entre as mulheres, característica herdeira do nosso passado escravocrata? Ou mesmo, será que as mulheres brasileiras abririam mão da tarefa de cuidar, caso o Estado assumisse essa função?

O enfrentamento da questão da violência de gênero no Brasil, a partir das políticas públicas, tem se distinguido por sua criminalização e judicialização (delegacias de mulheres e outras legislações) com pouca relação com as políticas de assistência social e outras. O que a nossa trajetória sociocultural do lugar de homens e mulheres tem a contribuir com essa significação?

Como o Estado brasileiro tem respondido e/ou pode responder à convivência de diversas formações familiares nos diferentes estratos socioeconômicos, bem como com a recorrência histórica das famílias chefiadas por mulheres e do trabalho feminino precário e informal, como um aspecto importante da desigualdade social no Brasil? O que seria mais eficaz, políticas de assistência social que tenham como foco as famílias mais pobres e chefiadas por mulheres ou o investimento no trabalho feminino em condições mais igualitárias e, para isso, fomentado por políticas públicas de trabalho, de educação, fiscal e outras?

O impacto das políticas neoliberais tem produzido falhas simultâneas em todas as esferas de produção do bem-estar social: Estados, mercados e famílias e encontra terreno propício para a reprivatização do bem-estar pelo intenso "familismo" que induz ideologicamente as famílias a se responsabilizarem com 
os cuidados com crianças, idosos e doentes, atribuição que recai majoritariamente sobre as mulheres.

As contradições da histórica condição social das mulheres brasileiras são enormes e tudo isso enlaçado por uma espantosa desigualdade social podemos constatar os enormes desafios que temos pela frente.

\section{Referências}

BEVERIDGE, W. The Beveridge report: full employment and allied services. 1942.

BOCK, G. Pobreza feminina, maternidade e direito das mães na ascensão dos Estados-Providência. In: DUBY, G.; PERROT, M. A história das mulheres no ocidente: o século XX. Porto: Afrontamento, 1994. p. 435-478.

CROMPTON, Rosemary; LYONETTE, Clare. Equilíbrio entre trabalho e vida na Grã-Bretanha e na Europa. In: ARAÚJO, Clara; PICANÇO, Felicia; SCALON, Celi (Orgs.) Novas conciliações e antigas tensões? Gênero, familia e trabalho em perspectiva comparada. São Pauloa: Edusc, 2007. p. 99-131.

ESPING-ANDERSEN, Gosta. Why we need a New Welfare State. Oxford: Oxford University Press, 2002.

FARIA, Carlos Aurélio Pimenta de. Uma genealogia das teorias e modelos do Estado de Bem-Estar Social. Revista Brasileira de Informação Bibliográfica em Ciências Sociais, Rio de Janeiro, n. 46, p. 38-71, 1998.

GIFFIN, Karen. Produção do conhecimento em um mundo "problemático": contribuições de um feminismo dialético e relacional. Estudos Feministas, Florianópolis, v. 14, n. 3, p. 635-653, set./dez. 2006.

GORNICK, Janet C.; MEYERS, Márcia K. Regimes de bem-estar social com relação a trabalho remunerado e cuidados. In: ARAÚJO, Clara; PICANÇO, Felicia; SCALON, Celi (Orgs.). Novas conciliações e antigas 
tensões? Gênero, família e trabalho em perspectiva comparada. São Paulo: Edusc, 2007. p. 191-221.

HIRATA, H.; KERGOAT, D. Novas configurações da divisão sexual do trabalho. Cadernos de Pesquisa, São Paulo, v. 37, n.132, p. 595609, set./dez. 2007.

JENSON, Jane. Who cares? Gender and welfare regimes. Social Politics, v. 4, n. 2, p. 77-99, 1997.

LÉFAUCHEUR, N. Maternidade, família e Estado. In: DUBY, G.; PERROT, M. A história das mulheres no ocidente: o século XX. Porto: Afrontamento, 1994. p. 479-503.

LEWIS, Jane. The decline of the male breadwinner model: the implications for work and care. Social Politics, v. 8, n. 2, p.152-170, 2001.

McINTOSH, Mary. Feminism and Social Policy. In: PIERSON, Christopher; CASTELS, Francis G. (Eds.). The Welfare State reader. Oxford (USA): Blackwell, 2000. p. 119-131.

MEULDERS, D. et al. Trabalho e maternidade na Europa, condições de trabalho e políticas públicas. Cadernos de pesquisa, Fundação Carlos Chagas, São Paulo, v. 37, n. 132, set/dez, 2007.

ORLOFF, Ann Shola. Farewell to Maternalism? State Policies and mothers' employment. [Evanston (IL): Institute for Policy Research, Northwestern University, [s. d.]. (Working Paper Series, WP-05-10).

PATEMAN, Carole. The patriarchal Welfare State. In: PIERSON, Christopher; CASTELS, Francis G. (Eds.). The Welfare State reader. Oxford (USA): Blackwell, 2000. p. 133-152.

SCOT'T, Joan W. O enigma da igualdade. Estudos Feministas, Florianópolis, v. 13, n. 1, p. 11-30, jan./abr. 2005.

SORJ, Bila; FONTES, Adriana. Políticas e práticas de conciliação entre família e trabalho. Cadernos de Pesquisa, Fundação Carlos Chagas, São Paulo, v. 37, n. 132, set./dez. 2007.

TORRES, Anália; MENDES, Rita; LAPA, Tiago. Família e trabalho na Europa. In: ARAÚJO, Clara; PICANÇO, Felicia; SCALON, Celi. 
68 Andrea Sousa Gama

(Orgs.). Novas conciliações e antigas tensões? Gênero, família e trabalho em perspectiva comparada. São Paulo: Edusc, 2007. p. 133-189.

Submetido em 11 setembro de 2008 e aceito em 27 novembro de 2008. 